\title{
Prediction of Canola Residue Characteristics Using Near-Infrared Spectroscopy
}

\author{
Tami L. Stubbs ${ }^{1}$ and Ann C. Kennedy ${ }^{2}$ \\ ${ }^{1}$ Department of Crop and Soil Sciences, Washington State University, 115 Johnson Hall, Pullman, WA 99164-6420, USA \\ ${ }^{2}$ Northwest Sustainable Agroecosystems Research Unit, USDA-ARS, 215 Johnson Hall, Pullman, WA 99164-6421, USA \\ Correspondence should be addressed to Tami L. Stubbs; tlstubbs@wsu.edu
}

Received 27 January 2017; Accepted 8 March 2017; Published 5 April 2017

Academic Editor: Manuel Tejada

Copyright (c) 2017 Tami L. Stubbs and Ann C. Kennedy. This is an open access article distributed under the Creative Commons Attribution License, which permits unrestricted use, distribution, and reproduction in any medium, provided the original work is properly cited.

\begin{abstract}
Little work has been done to characterize and quantify the residue traits affecting decomposition of winter and spring canola (Brassica napus L.) residue in dryland farming systems of the Pacific Northwest United States. Traditional methods of characterizing residue fiber and nutrients are time-consuming and expensive and require large quantities of chemical reagents. The goal of this research was to determine whether near-infrared spectroscopy (NIRS) could accurately predict neutral detergent fiber (NDF), acid detergent fiber (ADF), acid detergent lignin (ADL), carbon $(\mathrm{C})$, and nitrogen $(\mathrm{N})$ of canola stems, litter, and roots and decomposition of canola stems. Canola residue varied in decomposition, fiber, and nutrients by year, location, and type. NIRS predictions were successful for NDF and ADF in 2011 (standard error of prediction (SEP) $<2.67 ; R^{2}>0.95$ ) and NDF, ADF, and $\mathrm{N}$ in $2012\left(\mathrm{SEP}<2.38 ; R^{2}>0.91\right)$. Other predictions for residue fiber and nutrient characteristics were considered moderately successful. Prediction of canola residue decomposition with NIRS was useful for screening purposes. Near-infrared spectroscopy shows promise for rapidly and reproducibly predicting some canola residue fiber and nutrient traits and may be useful for estimating residue decomposition potential in dryland conservation cropping systems.
\end{abstract}

\section{Introduction}

Production of winter and spring canola (Brassica napus L.) is increasing in the Pacific Northwest (PNW) United States as marketing opportunities and profitability for growers surge upward. Worldwide, canola production has increased dramatically, and demand for canola oil and meal continues to rise [1]. In the United States in 2008-2009, domestic consumption of canola oil was more than 2.5 times domestic production [1]. Cultivars of winter and spring canola perform well in conventional and conservation farming systems, and higher yielding cultivars and herbicide resistant varieties have made these crops more economically feasible. A review by Johnston et al. [2] notes that canola is well-suited in conservation tillage systems, including no-till, and can result in increased wheat yields in rotation compared to continuous wheat crops.

In the dryland farming areas of the inland PNW, average annual rainfall varies from $150 \mathrm{~mm}$ to $500 \mathrm{~mm}$. Soils in the eastern portion of the region with higher rainfall and steeper slopes are cropped annually and are susceptible to erosion by water. The traditional cropping system in the western segment is a winter wheat-summer fallow system with conventional, high disturbance tillage, which leaves soils prone to wind erosion. Growers throughout the region are working to implement conservation farming practices to curb erosion and enhance soil quality; however, residue management is of concern to growers who wish to employ management practices such as no-till farming. There is limited information available on the decomposition of oilseed crop residue in both conventional and no-till systems [3,4], and little is known about the residue characteristics of canola cultivars that are currently grown or in development for production in dryland and irrigated cropping systems of the PNW.

A combination of factors must be considered in determining decomposition of crop residues. Among those characteristics are fiber [5] and nutrient content of the residue $[6,7]$. Neutral detergent fiber (NDF) of residue includes hemicellulose, cellulose, and lignin, which are the insoluble 
cell wall components. Acid detergent fiber (ADF) consists of the cellulose and lignin portions, with hemicellulose removed; and acid detergent lignin (ADL) is the portion remaining after cellulose is removed. Along with fiber components of residue, nutrient content, especially the $\mathrm{C} / \mathrm{N}$ of residue, is critical in determining potential of residue to decompose under field conditions. Traditional wet chemistry and combustion methods of fiber, carbon, and nitrogen analysis are time-consuming, expensive, and destructive to the sample. Near-infrared spectroscopy (NIRS) is a potential method for estimating decomposability, fiber, and nutrient content of crop residues that is reproducible, inexpensive, rapid, and nondestructive to the sample [8]. Previous research has shown NIRS to be an acceptable method to predict fiber components [9-11] and nitrogen $[12,13]$ of crop residue.

The objectives of this research were to develop calibration equations for winter and spring canola residue NDF, ADF, $\mathrm{ADL}, \mathrm{N}, \mathrm{C}, \mathrm{C} / \mathrm{N}$, and decomposition and to determine the feasibility of using NIRS to predict those characteristics in canola residue from various cultivars produced in different years in distinct growing locations. Our goal is to develop NIRS as a rapid screening method for predicting residue composition and decomposition potential in dryland oilseed crops. As growers seek diversification in their wheat-based cropping systems and marketing opportunities for oilseed crops advance, information on canola residue decomposition will be useful to growers who wish to incorporate winter and spring canola into their rotations. Analysis of canola residue nutrient content can be used in determining nitrogen fertilizer efficiency. Additionally, canola residue may be managed for the greatest economic success and soil quality benefits in both conventional and conservation farming systems.

\section{Materials and Methods}

2.1. Residue Collection. Canola residue was collected after harvest from University of Idaho Brassica Breeding and Research Program canola variety trials in 2011 and 2012. Winter canola residue was collected from trials at Odessa, WA, Moscow, ID, and Genesee, ID, and spring canola residue was sampled from trials located at Davenport, WA, Colfax, WA, and Moscow, ID [14]. Shoot residue from seven cultivars and four replications was sampled at each site, and root residue was sampled to a depth of $30 \mathrm{~cm}$ from select locations. Canola litter (leaves, pods, and small stems) was collected from each site. Of the seven spring canola cultivars sampled in 2011, only three were included in the 2012 trials, and so four new spring canola cultivars were substituted in the 2012 sampling. The sampling locations were selected to represent varying amounts of average annual precipitation in eastern Washington and northern Idaho. Winter and spring canola was produced under rainfed conditions at all sites except the irrigated winter canola site at Odessa, WA. Each cultivar was grown under the same management (tillage, planting, seeding rate, fertilization, and weed control) as the grower/cooperator. The trial design at each location was a randomized complete block with four replications. The experimental design was a completely randomized split splitplot, where year was the main plot and location and cultivar were the subplots. Stems and roots were separated, and roots were washed with water and dried. For fiber, nutrient, and NIRS analyses, residue samples were ground to pass a one $\mathrm{mm}$ sieve.

2.2. Laboratory Reference Data. Ground canola residue was enclosed in filter bags (ANKOM Technology Corp., Fairport, $\mathrm{NY}$ ) for determination of neutral detergent fiber (NDF), acid detergent fiber (ADF), and acid detergent lignin (ADL) using a modification of the Van Soest et al. [15] procedure. Neutral detergent fiber and acid detergent fiber were determined sequentially following processing with an ANKOM 200 Fiber Analyzer (ANKOM Technology Corp., Fairport, NY). Acid detergent lignin was determined following digestion in $72 \% \mathrm{H}_{2} \mathrm{SO}_{4}$. Ground residue samples were analyzed by dry combustion using a LECO TruSpec Analyzer (St. Joseph, MI) to determine total carbon $(\mathrm{C})$ and nitrogen $(\mathrm{N})$ and calculate $\mathrm{C} / \mathrm{N}$ ratios. For consistency, we chose to analyze litter (leaves, pods, and small stems), stem, and root residues separately, and only stem residue was used in the decomposition study.

Decomposition of canola stem residue was determined in a laboratory incubation study using a procedure similar to Summerell and Burgess [16]. Canola stem residue was cut into $5 \mathrm{~cm}$ lengths and oven-dried. A layer of Ritzville silt loam soil (oven-dried and brought to field capacity) was placed in a one-pint glass canning jar, followed by approximately $2.0 \mathrm{~g}$ of oven-dry canola stem residue, and covered with a second layer of soil to simulate buried residue. Another $2.0 \mathrm{~g}$ of stem residue was placed on the soil surface to simulate surface residue. Residue was dried and weighed prior to placing in soil. Jars were sealed with parafilm to allow air exchange and incubated at $22^{\circ} \mathrm{C}$. Residue from 2012 was used for the study and included the seven cultivars each of winter and spring canola from each site. Each cultivar was replicated three times. After an 11-week incubation period, canola residue was removed from soil, washed, dried, and reweighed to determine mass of residue lost during incubation.

2.3. Near-Infrared Spectroscopy. Near-infrared spectroscopy (NIRS) is a rapid, low cost, nondestructive secondary method that was used to predict fiber and nutrient content of canola root and shoot residue. Calibration and prediction equations were developed for canola residue enclosed in stationary metal ring cups (36 mm inside diameter) and scanned with a FOSS XDS Rapid Content Analyzer (Foss NIRSystems, Laurel, MD) using ISIscan software, version 3.10 (Infrasoft International, State College, PA). Samples were scanned twice using the wavelength range $400-2498 \mathrm{~nm}$ at $2 \mathrm{~nm}$ intervals. The mean of the two scans was used for data analysis. Canola stem, root, and litter data for the two years of the study were analyzed separately and each set was randomly divided into two parts for developing calibration equations (Table 1; 2011, $n=314 ; 2012, n=215)$ and for validation of equations (Table 2; 2011, $n=314 ; 2012, n=215$ ). Separate calibration equations and validation of equations were performed for the canola residue decomposition study (Table 3). For both the calibration and validation sets, $n=118$ buried residue 
TABLE 1: Calibration statistics for prediction of NDF, ADF, ADL, N, C, and C/N in 2011 and 2012 winter and spring canola residue using NIRS. Residue consisted of stems, litter (small stems, leaves, and pods), and roots.

(a) 2011 winter and spring canola residue

\begin{tabular}{lccccccccc}
\hline Component & Math treatment $^{\mathrm{a}}$ & $n$ & Mean $^{\mathrm{b}}$ & SD & SEC & $R^{2}$ & SECV & $1-\mathrm{VR}$ & SD/SECV \\
\hline NDF & $2,10,10,1$ & 297 & 71.57 & 10.21 & 2.10 & 0.96 & 2.24 & 0.95 & 4.56 \\
ADF & $2,10,10,1$ & 299 & 55.90 & 8.95 & 1.42 & 0.98 & 1.61 & 0.97 & 5.55 \\
ADL & $2,10,10,1$ & 304 & 13.12 & 2.39 & 0.75 & 0.90 & 0.83 & 0.88 & 2.72 \\
N & $2,10,10,1$ & 305 & 0.80 & 0.49 & 0.08 & 0.98 & 0.09 & 0.97 & 5.41 \\
C & $2,4,4,1$ & 299 & 43.80 & 2.99 & 0.61 & 0.96 & 0.74 & 0.94 & 4.05 \\
C/N & $2,4,4,1$ & 301 & 73.12 & 36.82 & 8.08 & 0.95 & 9.93 & 0.93 & 3.71 \\
\hline
\end{tabular}

(b) 2012 winter and spring canola residue

\begin{tabular}{lccccccccc}
\hline Component & Math treatment $^{\mathrm{a}}$ & $n$ & Mean $^{\mathrm{b}}$ & SD & SEC & $R^{2}$ & SECV & $1-\mathrm{VR}$ & SD/SECV \\
\hline NDF & $2,4,4,1$ & 205 & 73.20 & 7.08 & 1.29 & 0.97 & 1.59 & 0.95 & 4.44 \\
ADF & $2,4,4,1$ & 206 & 59.02 & 5.96 & 1.19 & 0.96 & 1.40 & 0.94 & 4.25 \\
ADL & $2,10,10,1$ & 205 & 13.34 & 2.01 & 0.75 & 0.86 & 0.83 & 0.83 & 2.41 \\
N & $3,5,5,1$ & 209 & 0.815 & 0.51 & 0.06 & 0.99 & 0.09 & 0.97 & 5.41 \\
C & $1,4,4,1$ & 207 & 42.34 & 2.09 & 0.62 & 0.91 & 0.69 & 0.89 & 3.03 \\
C/N & $2,10,10,1$ & 207 & 73.12 & 45.39 & 10.88 & 0.94 & 12.99 & 0.92 & 3.49 \\
\hline
\end{tabular}

NDF: neutral detergent fiber; ADF: acid detergent fiber; ADL: acid detergent lignin; N: nitrogen; C: carbon; C/N: carbon to nitrogen ratio; NIRS: near-infrared spectroscopy; SD: standard deviation; SEC: standard error of calibration; $R^{2}$ : coefficient of determination; SECV: standard error of cross validation; 1 - VR: 1 minus variance ratio.

${ }^{a}$ The scatter correction SNV and detrend was used. Math treatment: derivative number, gap (nm), smooth (number of smoothing points), and second smooth.

${ }^{\mathrm{b}}$ Mean percent NDF, ADF, ADL, C, and N.

TABLE 2: Reference measurements and validation results for the prediction of 2011 and 2012 winter and spring canola residue NDF, ADF, $\mathrm{ADL}, \mathrm{N}, \mathrm{C}$, and $\mathrm{C} / \mathrm{N}$ using NIRS.

(a) 2011 winter and spring canola residue

\begin{tabular}{|c|c|c|c|c|c|c|c|c|c|c|}
\hline \multirow[b]{2}{*}{ Component } & \multirow[b]{2}{*}{$n$} & \multicolumn{3}{|c|}{ Reference measurements } & \multicolumn{6}{|c|}{ Validation results } \\
\hline & & Range & Measured mean ${ }^{a}$ & Measured SD & NIRS predicted mean & Bias & $R^{2}$ & SEP & Slope & RPD \\
\hline NDF & 308 & $38.10-87.91$ & 69.6 & 11.56 & 69.86 & -0.262 & 0.95 & 2.67 & 0.99 & 4.33 \\
\hline $\mathrm{ADF}$ & 308 & $29.43-68.59$ & 54.66 & 9.61 & 54.79 & -0.131 & 0.96 & 1.85 & 1.00 & 5.19 \\
\hline $\mathrm{ADL}$ & 308 & $6.86-18.45$ & 12.89 & 2.46 & 12.74 & 0.148 & 0.89 & 0.87 & 0.92 & 2.83 \\
\hline $\mathrm{N}$ & 308 & $0.247-3.062$ & 0.828 & 0.53 & 0.836 & -0.008 & 0.89 & 0.18 & 0.97 & 2.94 \\
\hline $\mathrm{C}$ & 308 & $30.85-49.80$ & 43.68 & 3.22 & 43.64 & 0.038 & 0.83 & 1.34 & 0.97 & 2.40 \\
\hline $\mathrm{C} / \mathrm{N}$ & 308 & $11.95-193.94$ & 73.56 & 38.12 & 72.60 & 0.958 & 0.87 & 14.08 & 0.94 & 2.71 \\
\hline
\end{tabular}

(b) 2012 winter and spring canola residue

\begin{tabular}{|c|c|c|c|c|c|c|c|c|c|c|}
\hline \multirow[b]{2}{*}{ Component } & \multirow[b]{2}{*}{$n$} & \multicolumn{3}{|c|}{ Reference measurements } & \multicolumn{6}{|c|}{ Validation results } \\
\hline & & Range & Measured mean ${ }^{\mathrm{a}}$ & Measured SD & NIRS predicted mean & Bias & $R^{2}$ & SEP & Slope & RPD \\
\hline NDF & 214 & $48.69-84.36$ & 72.31 & 7.68 & 72.24 & 0.07 & 0.91 & 2.38 & 1.05 & 3.23 \\
\hline $\mathrm{ADF}$ & 214 & $39.89-69.25$ & 58.31 & 6.30 & 58.16 & 0.149 & 0.91 & 1.91 & 1.05 & 3.30 \\
\hline $\mathrm{ADL}$ & 214 & $7.59-44.43$ & 13.15 & 1.93 & 13.08 & 0.067 & 0.75 & 0.99 & 0.87 & 1.95 \\
\hline $\mathrm{N}$ & 214 & $0.181-3.446$ & 0.877 & 0.55 & 0.864 & 0.013 & 0.92 & 0.158 & 1.05 & 3.48 \\
\hline $\mathrm{C}$ & 214 & $33.41-46.01$ & 42.04 & 2.38 & 42.14 & -0.095 & 0.83 & 0.99 & 1.08 & 2.40 \\
\hline $\mathrm{C} / \mathrm{N}$ & 214 & $9.69-245.68$ & 72.71 & 48.26 & 71.28 & 1.438 & 0.89 & 16.5 & 1.07 & 2.92 \\
\hline
\end{tabular}

NDF: neutral detergent fiber; ADF: acid detergent fiber; ADL: acid detergent lignin; N: nitrogen; C: carbon; C/N: carbon to nitrogen ratio; NIRS: near-infrared spectroscopy; SD: standard deviation; $R^{2}$ : coefficient of determination; SEP: standard error of prediction; RPD: ratio of prediction to deviation (SD/SEP).

${ }^{\mathrm{a}}$ Mean percent NDF, ADF, ADL, C, and N. 
TABLE 3: Calibration statistics (a) and reference measurements and validation results (b) for prediction of 2012 canola stem residue decomposition in a laboratory incubation study using NIRS.

(a) Calibration statistics

\begin{tabular}{lccccccccc}
\hline Component & Math treatment $^{\mathrm{a}}$ & $n$ & Mean $^{\mathrm{b}}$ & SD & SEC & $R^{2}$ & SECV & $1-$ VR & SD/SECV \\
\hline Buried residue & $3,5,5,1$ & 116 & 49.03 & 10.79 & 3.15 & 0.92 & 5.21 & 0.77 & 2.07 \\
Surface-placed residue & $3,5,5,1$ & 117 & 43.98 & 10.68 & 5.06 & 0.78 & 5.65 & 0.72 & 1.89 \\
\hline
\end{tabular}

(b) Reference measurements and validation results

\begin{tabular}{|c|c|c|c|c|c|c|c|c|c|}
\hline & \multicolumn{4}{|c|}{ Reference measurements } & \multicolumn{5}{|c|}{ Validation results } \\
\hline & $n$ & Range & Measured mean & Measured SD & NIRS predicted mean & Bias & $R^{2}$ & SEP & Slope \\
\hline Buried residue & 118 & $27.35-73.86$ & 49.03 & 11.58 & 49.01 & 0.028 & 0.63 & 7.12 & 0.88 \\
\hline Surface-placed residue & 118 & $23.93-63.82$ & 43.49 & 11.41 & 44.59 & -1.093 & 0.67 & 6.67 & 0.97 \\
\hline
\end{tabular}

NIRS: near-infrared spectroscopy; SD: standard deviation; SEC: standard error of calibration; $R^{2}$ : coefficient of determination; SECV: standard error of cross validation; 1 - VR: 1 minus variance ratio; SEP: standard error of prediction.

${ }^{\mathrm{a}}$ The scatter correction SNV and detrend was used. Math treatment: derivative number, gap (nm), smooth (number of smoothing points), and second smooth.

${ }^{\mathrm{b}}$ Mean percent of stem mass lost.

samples and $n=118$ surface-placed residue samples. Reference analysis and NIRS analysis were performed on each of the samples in both sets. Random selection of sample sets and calibration and validation statistics were completed using WinISI software, version 4.0 (Infrasoft International, State College, PA). Calibration equations were derived using modified partial least-squares (MPLS) and cross-validation techniques. The scatter correction of standard normal variant and detrend (SNV-D) was applied, along with several different math treatments for derivative order number, gap, and first smoothing. The second smoothing was set at 1 to indicate no second smoothing. Principal component analysis was used to identify and remove spectral outliers. Samples having spectra with Mahalanobis distance $(H)$ values greater than 3.0 were considered outliers and were removed from the file. The appropriate calibration equation for each component was determined by selecting the one with the lowest standard error of cross-validation (SECV) and the 1 - variance ratio $(1-\mathrm{VR})$ closest to 1 [8]. The ratio of standard deviation (SD)/SECV was calculated [17] and used to determine calibration equations that were acceptable for quantitative prediction of fiber characteristics (Tables 1 and 3). Correlations between NIRS-predicted values and reference values (fiber wet chemistry, LECO TruSpec, or residue decomposition) were determined using Pearson correlation coefficients [18] with JMP software [19].

\section{Results and Discussion}

3.1. Calibration Results. In the present study, the residue of commonly grown cultivars of winter and spring canola produced at multiple locations were analyzed for neutral detergent fiber (NDF), acid detergent fiber (ADF), acid detergent lignin $(\mathrm{ADL})$, carbon $(\mathrm{C})$, and nitrogen $(\mathrm{N})$ contents and decomposition in lab incubations. Traditional methods to quantify fiber and nutrient content of plant residues are laborious; destroy the plant sample; and are unfriendly to the environment. Near-infrared spectroscopy (NIRS) represents a secondary method to estimate fiber and nutrient content which is of lower cost and nondestructive to the crop sample. Near-infrared spectroscopy is reliable and accurate and requires very little sample preparation [8], while allowing for rapid analysis of multiple properties at one time [20]. Sample characteristics are quantitatively predicted by NIRS using the near-infrared absorbance of a sample to measure organic functional groups. In the present study, stem, root, and litter residue from winter and spring canola cultivars grown at multiple locations over two years were scanned with a FOSS XDS Rapid Content Analyzer, and those results were compared to laboratory reference data from fiber, nutrient, and decomposition experiments to develop calibration equations for prediction of those characteristics. Predictions of canola shoot, root, and litter residue characteristics, as well as canola stem residue decomposition, using NIRS were conducted as part of the present study.

Calibration statistics for prediction equations of winter and spring canola residue traits are listed in Table 1. Separate calibrations were done for each year of the study, with Table 1(a) showing results for residue from 2011 and Table 1(b) for residue from 2012. The math treatments which resulted in most optimal calibration statistics were used for the traits of NDF, ADF, ADL, N, C, and C/N. Using equations developed with specific math treatments improves the predictability for individual data sets [21]. Equations that yielded the $1-\mathrm{VR}$ values closest to 1 and the lowest SECV values were chosen for predictions. For 2011 winter and spring canola residue, $\mathrm{NDF}, \mathrm{ADF}$, and ADL, 1 - VR values were $0.95,0.97$, and 0.88 , and SECV values were $2.24,1.61$, and 0.83 . Nitrogen, C, and $\mathrm{C} / \mathrm{N} 1-\mathrm{VR}$ and SECV values for 2011 were $0.97,0.94$, and 0.93 and $0.09,0.74$, and 9.93, respectively. The NDF, ADF, and ADL 1 - VR and SECV values for 2012 canola residue were $0.95,0.94$, and 0.83 and $1.59,1.40$, and 0.83 . The 2012 $1-\mathrm{VR}$ and SECV for N, C, and C/N were 0.97, 0.89, and 0.92 and $0.09,0.69$, and 12.99. Deaville et al. [17] developed guidelines for the predictive ability of calibration equations using SD/SECV values. Under their protocol, calibrations with SD/SECV ratios $>3.0$ are acceptable for prediction of characteristics using NIRS. Ratios $>2.5$ but $<3.0$ indicate calibrations that would be useful for screening, and equations with SD/SECV $<2.5$ are not useful for making predictions. 


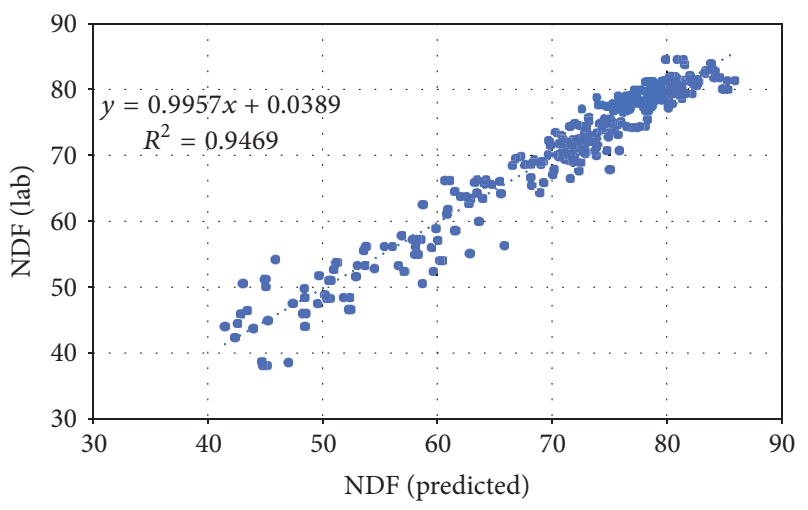

FIGURE 1: Linear regression relationship between laboratory reference methods and NIRS-predicted values for NDF $\left(R^{2}=0.95\right)$ of winter and spring canola from 2011 on a dry weight basis.

In this study, all SD/SECV values for 2011 were greater than 3.0 except ADL (2.72; Table 1), indicating that successful calibrations were developed for the traits of NDF, ADF, N, C, and $\mathrm{C} / \mathrm{N}$ (SD/SECV ranging from 3.71 to 5.55 ). The same was true for 2012, with SD/SECV values ranging from 3.03 to 5.41 for all traits but ADL (2.41; Table 1). In 2011, the SD/SECV of 2.72 for ADL fell within the range that would be acceptable for screening of traits; however, in 2012 the SD/SECV for ADL was only 2.41 , which is outside the range considered acceptable for a screening prediction.

3.2. Validation Results. Reference measurements and validation results are shown in Table 2(a) for 2011 winter and spring canola residue and Table 2(b) for 2012 canola residue samples. In both years, acceptable predictions were attained for each of the residue traits. With 2011 residue, $R^{2}$ values ranged from 0.83 to 0.96 , and $R^{2}$ values for 2012 residue ranged from 0.75 to 0.92 . For all traits in both years, slope values were near 1 , with the lowest slope $=0.87$ for $\mathrm{ADL}$ in 2012. Comparisons of laboratory reference values for each trait as compared to NIRS-predicted values are shown in Figures 1-6. Because similar results were obtained for the two years of the study, only results from 2011 are shown. In determining whether NIRS is an acceptable method for prediction of residue traits, Mathison et al. [22] used an additional calculation, ratio of prediction to deviation (RPD), which is the measured standard deviation (SD) divided by the standard error of prediction (SEP) of the validation results. When RPD values are $>2.5$, the predictions are considered to be acceptable, while RPD values of 10 are excellent [22]. In this study, all RPD values indicated acceptable predictions except for ADL in $2012(\mathrm{RPD}=1.95)$ and $\mathrm{C}$ in both years of the study $(2011 \mathrm{RPD}=2.40 ; 2012 \mathrm{RPD}=2.40)$. The highest RPD values were NDF (4.33) and ADF (5.20) in 2011. Malley et al. [23] include a separate calculation, RER, in determining suitable predictions using NIRS. The RER is equal to the range of measured reference values divided by the SEP with RER values of $>20$ considered to be excellent, RER 15-20 successful, RER 10-15 moderately successful, and RER 8-10 moderately useful [23]. In this study, we calculated RER

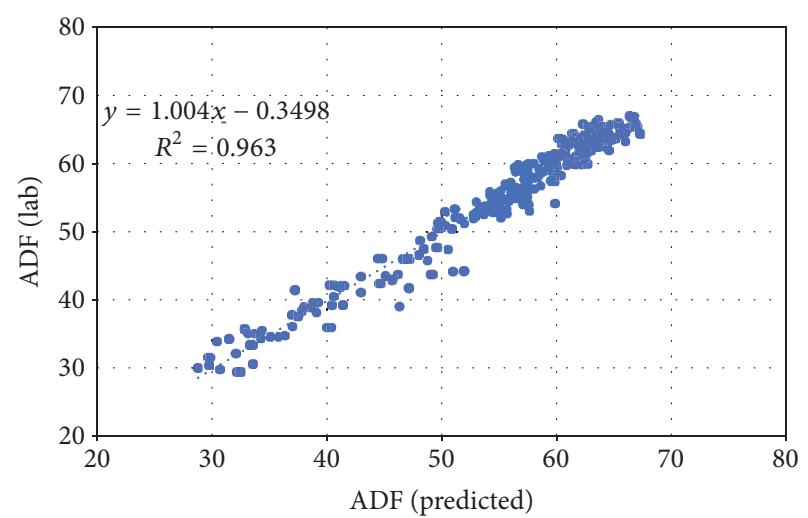

FIGURE 2: Linear regression relationship between laboratory reference methods and NIRS-predicted values for $\operatorname{ADF}\left(R^{2}=0.96\right)$ of winter and spring canola from 2011 on a dry weight basis.

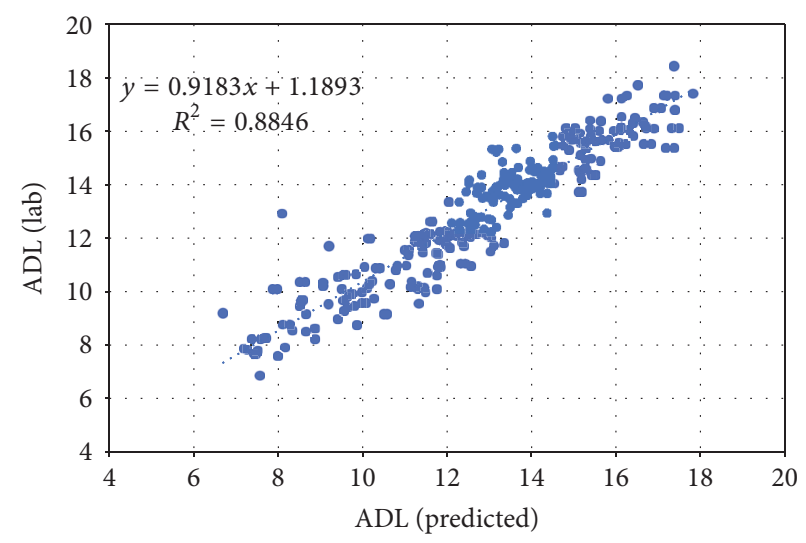

FIGURE 3: Linear regression relationship between laboratory reference methods and NIRS-predicted values for ADL $\left(R^{2}=0.89\right)$ of winter and spring canola from 2011 on a dry weight basis.

values ranging from 12.73 to 37.21 (data not shown); however, these values gave conflicting results when compared to the guidelines using $R^{2}$ and RPD values in determining success of predictions. Roggo et al. [24] suggested that RPD values of $>3$ and RER values $>10$ may have use for screening characteristics in their study of sugar beet (Beta vulgaris) quality. In our study, only NDF and ADF consistently met that level for RPD, while the RER values for each characteristic would indicate acceptable predictions for screening fiber and nutrient traits of canola residue.

3.3. Prediction of Canola Residue Decomposition. Canola stem residue decomposition was measured in a laboratory incubation study [14], and the percent decomposition was compared to NIRS-predicted values. The calibration statistics and validation results are shown in Table 3 . The SD/SECV values were 2.07 for buried residue, as in a conventionally tilled farming system, and 1.89 for residue that was surfaceplaced, as in no-till farming. Using the guidelines proposed by Deaville et al. [17], these calibration equations would be unacceptable for predicting canola residue decomposition using NIRS. Validation results yielded $R^{2}$ values of 0.63 for 


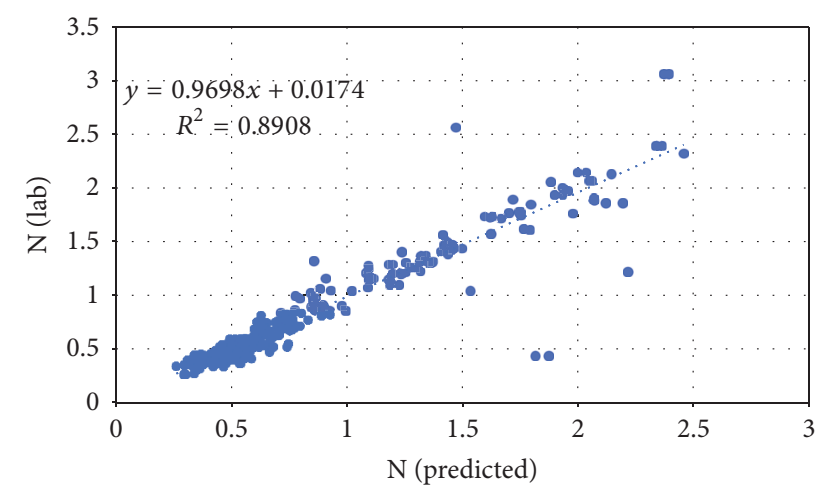

FIGURE 4: Linear regression relationship between laboratory reference methods and NIRS-predicted values for $\mathrm{N}\left(R^{2}=0.89\right)$ of winter and spring canola from 2011 on a dry weight basis.

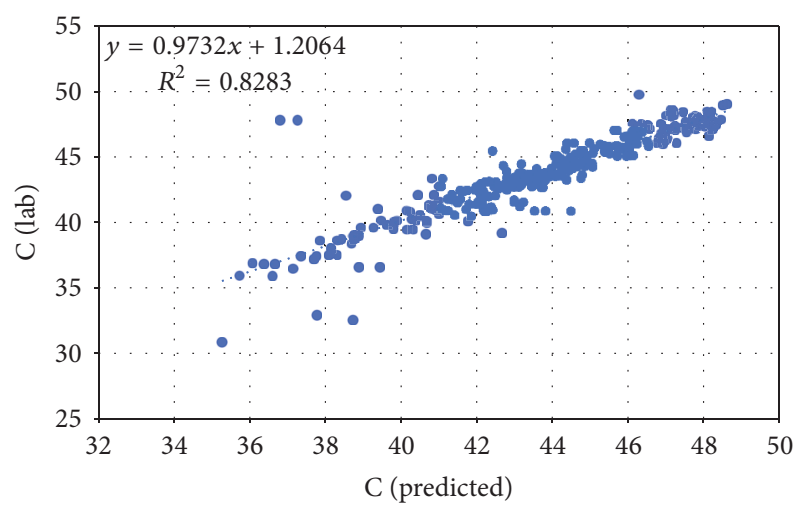

FIGURE 5: Linear regression relationship between laboratory reference methods and NIRS-predicted values for C $\left(R^{2}=0.83\right)$ of winter and spring canola from 2011 on a dry weight basis.

buried residue and 0.67 for surface-placed residue. The RPD values were 1.63 for buried canola stems and 1.71 for surfaceplaced residue, and both values are considered unsuitable for screening; however, Pearson correlation coefficients were all $>0.77$ when comparing laboratory canola residue decomposition with NIRS-predicted values $(P>0.05$; data not shown). Difficulties in cleaning soil from decomposing residue may have led to variability in the reference measurements [16]. Shepherd et al. [25] found that NIRS has the potential for accurately determining decomposition of organic residues. Additional studies with a larger number of canola residue samples may be needed to develop stronger calibrations in order to use NIRS for predicting canola residue decomposition in soil.

3.4. Correlation between Laboratory Reference Measurements and NIRS-Predicted Measurements. NIRS-predicted values were significantly correlated $(P>0.05)$ with measured reference values for each of the residue fiber and nutrient characteristics tested when calculated across the two years, six study locations, two crop types, and all plant components (Table 4). The six traits of NDF, ADF, ADL, N, C, and C/N were all well-correlated with one another, with correlation coefficients

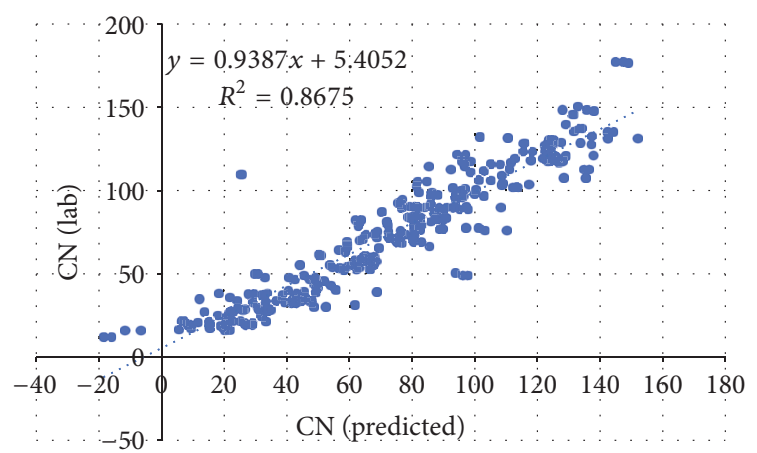

FIGURE 6: Linear regression relationship between laboratory reference methods and NIRS-predicted values for C/N $\left(R^{2}=0.87\right)$ of winter and spring canola from 2011 on a dry weight basis.

$\geq 0.92$ (level of significance $<0.0001$ ). Nitrogen was negatively correlated with each of the other characteristics. Correlations between the fiber fractions (NDF, ADF, and ADL) were higher than those with the nutrient contents $(\mathrm{N}, \mathrm{C}$, and $\mathrm{C} / \mathrm{N})$. We previously found that NIRS was a successful method for predicting NDF, ADF, and ADL in cereal crop residue, but not for C and N [26]. Velasco and Mollers [12] successfully used NIRS to accurately predict N concentration in Brassica napus L. tissues. Additional work has shown the usefulness of NIRS in predicting features of canola seed [27] and/or meal [28]. Long et al. [29] found that NIRS could measure the oil content of canola seed prior to crushing. Wittkop et al. [30] used NIRS to predict NDF, ADF, and ADL in intact seed of various genotypes of oilseed rape (Brassica napus L.). They found good $R^{2}$ values for $\mathrm{ADL}$ and adequate predictions for $\mathrm{NDF}$ and ADF when looking for low fiber genotypes. Others have studied properties of canola residue for decomposition $[4,31]$, biofuel production [32], and pulp or paper production [33]; however, we are unaware of attempts to develop NIRS calibrations for prediction of canola residue properties for those purposes.

Like other crop plants [34,35], various components of the canola postharvest residue have differing nutrient and fiber contents [14] and have varying rates of residue decomposition [31]. We found that NIRS-predicted values for fiber and nutrient content of canola stems, litter, and roots were wellcorrelated when compared to laboratory reference methods (Table 5). The highest correlation coefficient for stem residue was for ADF (0.97) and the lowest was for ADL (0.90). Canola litter, which included leaves, pods, and very small stems, had the highest correlation for ADF as well (0.92) and the lowest for $\mathrm{C}(0.62)$. The highest Pearson correlation coefficient for canola roots was with $\mathrm{N}(0.98)$, and the lowest was with ADL (0.80).

Crop residues, including canola, vary in fiber and nutrient content among years [3,36], crop types [3,37], and growing locations $[36,38]$. There was significant correlation between laboratory reference measurements and NIRS predictions for all traits in both years, both crop types, and the six field experiment locations (Table 6; $P>0.05$; level of significance $<0.0001$ for all comparisons). The highest correlations were found for samples when separated by year, with the highest 
TABLE 4: Pearson correlation coefficients for canola residue traits measured using laboratory reference methods and compared to NIRS predicted values across all years, locations, plant components, and canola types. For each pair, the level of significance was $<0.0001$ at $P<0.05$ $(n=522)$.

\begin{tabular}{lcccccc}
\hline & NDF & ADF & ADL & N & C & 0.6322 \\
NDF & 0.9683 & 0.9511 & 0.8773 & -0.5546 & -0.5636 & 0.6204 \\
ADF & & 0.9760 & 0.8396 & -0.4931 & 0.6217 & 0.6516 \\
ADL & & 0.9187 & 0.9496 & -0.7810 & 0.5182 \\
N & & & & 0.9162 & -0.8484 \\
C & & & & 0.7867 \\
C/N & & & & 0.9349 \\
\hline
\end{tabular}

NIRS: near-infrared spectroscopy; NDF: neutral detergent fiber; ADF: acid detergent fiber; ADL: acid detergent lignin; N: nitrogen; C: carbon; C/N: carbon to nitrogen ratio.

TABLE 5: Pearson correlation coefficients for residue traits of canola plant components measured using laboratory reference methods and compared to NIRS predicted values across all years, locations, and canola types. For each pair, the level of significance was $<0.0001$ at $P<0.05$.

\begin{tabular}{lccccccc}
\hline & $n$ & NDF & ADF & ADL & N & C & C/N \\
\hline Stems & 346 & 0.9661 & 0.9722 & 0.8974 & 0.9702 & 0.9624 & 0.9442 \\
Litter & 65 & 0.8062 & 0.9226 & 0.7539 & 0.7791 & 0.6239 & 0.722 \\
Roots & 110 & 0.9013 & 0.8883 & 0.8025 & 0.975 & 0.8242 & 0.9116 \\
\hline
\end{tabular}

NIRS: near-infrared spectroscopy; NDF: neutral detergent fiber; ADF: acid detergent fiber; ADL: acid detergent lignin; N: nitrogen; C: carbon; C/N: carbon to nitrogen ratio.

TABLE 6: Pearson correlation coefficients for spring and winter canola residue traits measured using laboratory reference methods and compared to NIRS predicted values over two years and three locations for each crop type. For each pair, the level of significance was $<0.0001$ at $P<0.05$.

\begin{tabular}{|c|c|c|c|c|c|c|c|}
\hline & $n$ & NDF & $\mathrm{ADF}$ & ADL & $\mathrm{N}$ & $\mathrm{C}$ & $\mathrm{C} / \mathrm{N}$ \\
\hline \multicolumn{8}{|l|}{ Year } \\
\hline 2011 & 158 & 0.9255 & 0.936 & 0.9148 & 0.9798 & 0.9607 & 0.9366 \\
\hline 2012 & 153 & 0.9302 & 0.9298 & 0.8278 & 0.9647 & 0.9473 & 0.9506 \\
\hline \multicolumn{8}{|l|}{ Crop type } \\
\hline Spring & 161 & 0.753 & 0.7825 & 0.8507 & 0.8964 & 0.9319 & 0.8201 \\
\hline Winter & 150 & 0.8261 & 0.8539 & 0.7886 & 0.9514 & 0.911 & 0.8959 \\
\hline \multicolumn{8}{|l|}{ Location } \\
\hline Colfax, spring & 55 & 0.8051 & 0.7311 & 0.8354 & 0.9052 & 0.9566 & 0.6923 \\
\hline Davenport, spring & 51 & 0.804 & 0.8421 & 0.817 & 0.9088 & 0.902 & 0.8976 \\
\hline Moscow, spring & 55 & 0.6666 & 0.7285 & 0.8925 & 0.7321 & 0.929 & 0.7346 \\
\hline Odessa, winter & 58 & 0.8139 & 0.8502 & 0.8002 & 0.9225 & 0.6885 & 0.8059 \\
\hline Genesee, winter & 42 & 0.6347 & 0.7001 & 0.5523 & 0.9744 & 0.8863 & 0.879 \\
\hline Moscow, winter & 50 & 0.8614 & 0.8583 & 0.8398 & 0.9353 & 0.9429 & 0.8685 \\
\hline
\end{tabular}

NIRS: near-infrared spectroscopy; NDF: neutral detergent fiber; ADF: acid detergent fiber; ADL: acid detergent fiber; N: nitrogen; C: carbon; C/N: carbon to nitrogen ratio.

correlation for $\mathrm{N}$ in 2011 (0.98) and the lowest for ADL in 2011 (0.83). When samples were separated by crop type, the highest correlation was found for $\mathrm{N}$ in winter canola (0.95) and the lowest for NDF in spring canola (0.75). For the spring canola locations, the correlation coefficient was highest for $C$ from the Colfax, WA, location (0.96) and lowest for NDF from Moscow, ID, spring canola (0.67). In winter canola, the highest correlation coefficient was for $\mathrm{N}$ from Genesee, ID, residue (0.97), and the lowest coefficient was also from the Genesee location for ADL (0.55). Bruun et al. [39] were able to distinguish differences in ash content and degradability among cultivars of wheat straw grown at two sites in Denmark using NIRS predictions.

In previous work, we found that there were no clear differences in fiber or nutrient characteristics among residue samples from various cultivars of winter and spring canola grown in eastern Washington and northern Idaho [14]. In the present study, $n$ values were too low to develop calibration equations with adequate sets of validation data for individual winter and spring canola cultivars (data not shown). Redaelli and Berardo [11] found that NIRS could accurately predict fiber components of oat (Avena sativa L.) hulls grown in Italy 
and that fiber components varied with cultivar, but location played a lesser role in that variation. Oilseed rape genotypes showed variability in ADL with NIRS analysis according to Wittkop et al. [30]. Future work in this area might focus on obtaining a greater number of canola residue samples over more years or experimental locations to determine whether NIRS predictions are feasible for defining differences in residue traits among cultivars, establishing usefulness of NIRS for prediction of fiber and nutrient content of individual plant components, and verifying fertilizer uptake and nutrient efficiency in Brassica crops.

\section{Conclusions}

NIRS was successful in predicting the characteristics of NDF, $\mathrm{ADF}, \mathrm{N}$, and $\mathrm{C} / \mathrm{N}$ of winter and spring canola residue from two years of field studies. NIRS-predicted values were less consistent for ADL, where the prediction was successful for only one of the two years of the study. In this work, we found that NIRS was useful only for screening canola residue $\mathrm{C}$ and decomposition in the laboratory incubation studies, not for prediction of these two traits. NIRS predictions show promise for rapidly discerning differences in certain fiber and nutrient characteristics among canola residue samples while using smaller quantities of chemicals and performing less costly analyses. Ultimately, the rapid screening of crop residues for nutrient and fiber characteristics will provide information to crop producers and scientists for designing conservation cropping systems that make efficient use of fertilizers, increase soil organic matter, prevent soil erosion, and lead to soils with greater productivity.

\section{Conflicts of Interest}

The authors declare that they have no conflicts of interest.

\section{Acknowledgments}

The authors gratefully acknowledge the funding received from the Pacific Northwest Regional Canola Research Program and the assistance from Jim Davis, Jack Brown, and Megan Wingerson of the University of Idaho Brassica Breeding and Research Program. They are grateful to Jeremy Hansen, Brianna Kemp, and Mackenzie Owen for excellent technical assistance.

\section{References}

[1] United States Department of Agriculture-Economic Research Service, "Soybeans \& Oil Crops-Canola," 2012, http://www.ers .usda.gov/topics/crops/soybeans-oil-crops/canola.aspx\%23trade\#.UrCXUeKmbdU.

[2] A. M. Johnston, D. L. Tanaka, P. R. Miller et al., "Oilseed crops for semiarid cropping systems in the northern Great Plains," Agronomy Journal, vol. 94, no. 2, pp. 231-240, 2002.

[3] Y. K. Soon and M. A. Arshad, "Comparison of the decomposition and $\mathrm{N}$ and $\mathrm{P}$ mineralization of canola, pea and wheat residues," Biology and Fertility of Soils, vol. 36, no. 1, pp. 10-17, 2002.
[4] A. J. Franzluebbers, M. A. Arshad, and J. A. Ripmeester, "Alterations in canola residue composition during decomposition," Soil Biology and Biochemistry, vol. 28, no. 10-11, pp. 1289-1295, 1996.

[5] D. C. Wolf and G. H. Wagner, "Carbon transformations and soil organic matter formation," in Principles and Applications of Soil Microbiology, D. M. Sylvia, J. J. Fuhrman, R. G. Hartel, and D. A. Zuberer, Eds., pp. 285-332, Prentice-Hall, Upper Saddle River, NJ, USA, 2005.

[6] J. H. Smith and C. L. Douglas, "Wheat straw decomposition in the field," Soil Science Society of America Journal, vol. 35, no. 2, pp. 269-272, 1971.

[7] C. A. Palm and A. P. Rowland, "A minimum dataset for characterization of plant quality for decomposition," in Driven by Nature: Plant Litter Quality and Decomposition, G. Cadisch and K. E. Giller, Eds., pp. 379-392, CAB International, Wallingford, UK, 1997.

[8] Foss North America, ISIscan \& WinISI Software Training Class, 2008.

[9] M. K. D. Rambo, E. P. Amorim, and M. M. C. Ferreira, "Potential of visible-near infrared spectroscopy combined with chemometrics for analysis of some constituents of coffee and banana residues," Analytica Chimica Acta, vol. 775, pp. 41-49, 2013.

[10] Z. Nie, G. F. Tremblay, G. Bélanger et al., "Near-infrared reflectance spectroscopy prediction of neutral detergent-soluble carbohydrates in timothy and alfalfa," Journal of Dairy Science, vol. 92, no. 4, pp. 1702-1711, 2009.

[11] R. Redaelli and N. Berardo, "Prediction of fibre components in oat hulls by near infrared reflectance spectroscopy," Journal of the Science of Food and Agriculture, vol. 87, no. 4, pp. 580-585, 2007.

[12] L. Velasco and C. Mollers, "Use of near-infrared reflectance spectroscopy to assess nitrogen concentration in different plant tissues of rapeseed," Communications in Soil Science and Plant Analysis, vol. 31, no. 19-20, pp. 2987-2995, 2000.

[13] G.-C. Zhang, Z. Li, X.-M. Yan et al., "Rapid analysis of apple leaf nitrogen using near infrared spectroscopy and multiple linear regression," Communications in Soil Science and Plant Analysis, vol. 43, no. 13, pp. 1768-1772, 2012.

[14] T. L. Stubbs and A. C. Kennedy, "Characterization and decomposition of residue from winter and spring canola cultivars," Agronomy, In press.

[15] P. J. Van Soest, J. B. Robertson, and B. A. Lewis, "Methods for dietary fiber, neutral detergent fiber, and nonstarch polysaccharides in relation to animal nutrition," Journal of Dairy Science, vol. 74, no. 10, pp. 3583-3597, 1991.

[16] B. A. Summerell and L. W. Burgess, "Decomposition and chemical composition of cereal straw," Soil Biology and Biochemistry, vol. 21, no. 4, pp. 551-559, 1989.

[17] E. R. Deaville, D. J. Humphries, and D. I. Givens, "Whole crop cereals. 2. Prediction of apparent digestibility and energy value from in vitro digestion techniques and near infrared reflectance spectroscopy and of chemical composition by near infrared reflectance spectroscopy," Animal Feed Science and Technology, vol. 149, no. 1-2, pp. 114-124, 2009.

[18] R. G. D. Steel, J. H. Torrie, and D. A. Dickey, Principles and Procedures of Statistics, McGraw-Hill, New York, NY, USA, 1997.

[19] SAS Institute Inc, Using JMP 11, SAS Institute Inc, Cary, NC, USA, 2013.

[20] J. Stuth, A. Jama, and D. Tolleson, "Direct and indirect means of predicting forage quality through near infrared reflectance 
spectroscopy," Field Crops Research, vol. 84, no. 1-2, pp. 45-56, 2003.

[21] A. Ruano-Ramos, A. García-Ciudad, and B. García-Criado, "Determination of nitrogen and ash contents in total herbage and botanical components of grassland systems with near infrared spectroscopy," Journal of the Science of Food and Agriculture, vol. 79, no. 1, pp. 137-143, 1999.

[22] G. W. Mathison, H. Hsu, R. Soofi-Siawash et al., "Prediction of composition and ruminai degradability characteristics of barley straw by near infrared reflectance spectroscopy," Canadian Journal of Animal Science, vol. 79, no. 4, pp. 519-523, 1999.

[23] D. F. Malley, C. McClure, P. D. Martin, K. Buckley, and W. P. McCaughey, "Compositional analysis of cattle manure during composting using a field-portable near-infrared spectrometer," Communications in Soil Science and Plant Analysis, vol. 36, no. 4-6, pp. 455-475, 2005.

[24] Y. Roggo, L. Duponchel, and J.-P. Huvenne, "Quality evaluation of sugar beet (Beta vulgaris) by near-infrared spectroscopy," Journal of Agricultural and Food Chemistry, vol. 52, no. 5, pp. 1055-1061, 2004.

[25] K. D. Shepherd, B. Vanlauwe, C. N. Gachengo, and C. A. Palm, "Decomposition and mineralization of organic residues predicted using near infrared spectroscopy," Plant and Soil, vol. 277, no. 1-2, pp. 315-333, 2005.

[26] T. L. Stubbs, A. C. Kennedy, and A.-M. Fortuna, "Using NIRS to predict fiber and nutrient content of dryland cereal cultivars," Journal of Agricultural and Food Chemistry, vol. 58, no. 1, pp. 398-403, 2010.

[27] N. H. Hom, H. C. Becker, and C. Möllers, "Non-destructive analysis of rapeseed quality by NIRS of small seed samples and single seeds," Euphytica, vol. 153, no. 1-2, pp. 27-34, 2007.

[28] P. Si, R. J. Mailer, N. Galwey, and D. W. Turner, "Influence of genotype and environment on oil and protein concentrations of canola (Brassica napus L.) grown across southern Australia," Australian Journal of Agricultural Research, vol. 54, no. 4, pp. 397-407, 2003.

[29] D. S. Long, J. D. McCallum, F. L. Young, and A. W. Lenssen, "Instream measurement of canola (Brassica napus L.) seed oil concentration using in-line near infrared reflectance spectroscopy," Journal of Near Infrared Spectroscopy, vol. 20, no. 3, pp. 387-395, 2012.

[30] B. Wittkop, R. J. Snowdon, and W. Friedt, "New NIRS calibrations for fiber fractions reveal broad genetic variation in Brassica napus seed quality," Journal of Agricultural and Food Chemistry, vol. 60, no. 9, pp. 2248-2256, 2012.

[31] P. V. Blenis, P. S. Chow, and G. R. Stringam, "Effects of burial, stem portion and cultivar on the decomposition of canola straw," Canadian Journal of Plant Science, vol. 79, no. 1, pp. 97100, 1999.

[32] N. George, Y. Yang, Z. Wang, R. Sharma-Shivappa, and K. Tungate, "Suitability of canola residue for cellulosic ethanol production," Energy and Fuels, vol. 24, no. 8, pp. 4454-4458, 2010.

[33] R. Hosseinpour, P. Fatehi, A. J. Latibari, Y. Ni, and S. Javad Sepiddehdam, "Canola straw chemimechanical pulping for pulp and paper production,” Bioresource Technology, vol. 101, no. 11, pp. 4193-4197, 2010.

[34] H. P. Collins, L. F. Elliott, R. W. Rickman, D. F. Bezdicek, and R. I. Papendick, "Decomposition and interactions among wheat residue components," Soil Science Society of America Journal, vol. 54, no. 3, pp. 780-785, 1990.
[35] M. Quemada and M. L. Cabrera, "Carbon and nitrogen mineralized from leaves and stems of four cover crops," Soil Science Society of America Journal, vol. 59, no. 2, pp. 471-477, 1995.

[36] S. C. Rao, "Regional environment and cultivar effects on the quality of wheat straw," Agronomy Journal, vol. 81, no. 6, pp. 939943, 1989.

[37] N. Z. Lupwayi, G. W. Clayton, J. T. O’Donovan, K. N. Harker, T. K. Turkington, and W. A. Rice, "Decomposition of crop residues under conventional and zero tillage," Canadian Journal of Soil Science, vol. 84, no. 4, pp. 403-410, 2004.

[38] T. L. Stubbs, A. C. Kennedy, P. E. Reisenauer, and J. W. Burns, "Chemical composition of residue from cereal crops and cultivars in dryland ecosystems," Agronomy Journal, vol. 101, no. 3, pp. 538-545, 2009.

[39] S. Bruun, J. W. Jensen, J. Magid, J. Lindedam, and S. B. Engelsen, "Prediction of the degradability and ash content of wheat straw from different cultivars using near infrared spectroscopy," Industrial Crops and Products, vol. 31, no. 2, pp. 321-326, 2010. 


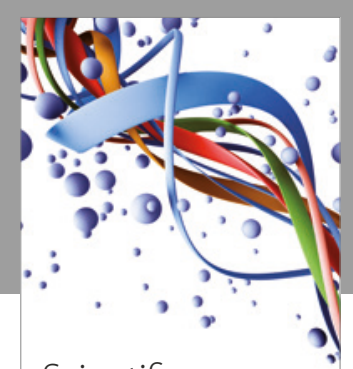

Scientifica
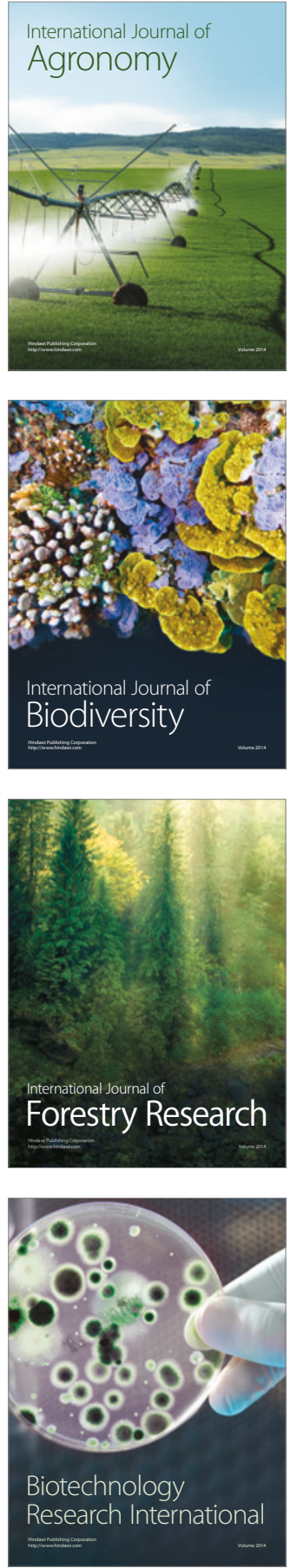
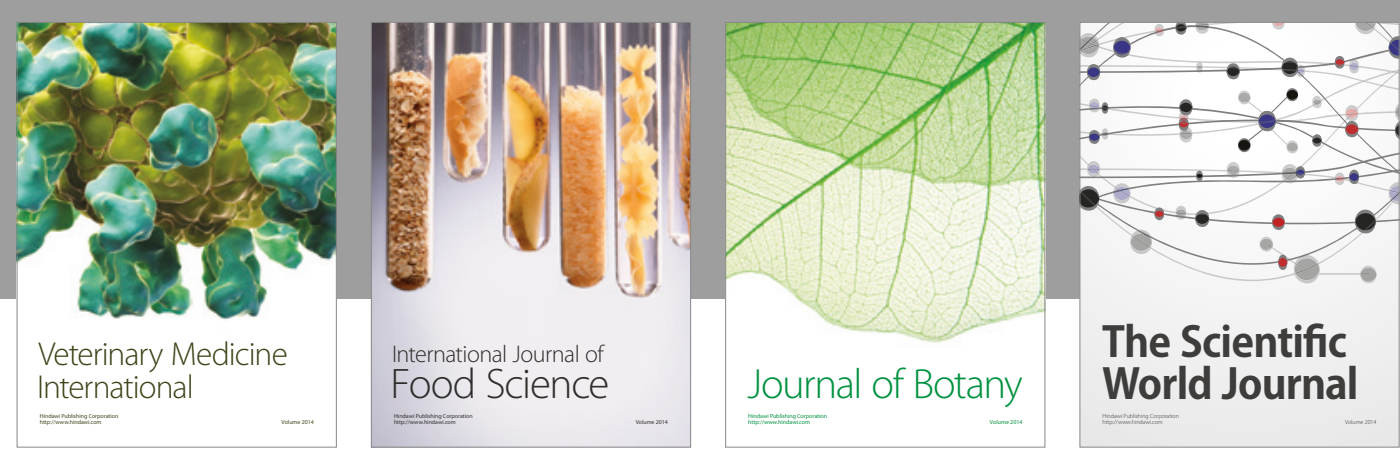

The Scientific

\section{World Journal}

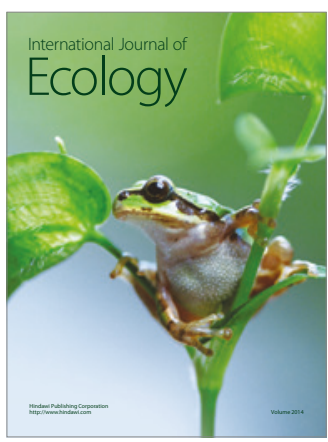

\section{Hindawi}

Submit your manuscripts at

https://www.hindawi.com
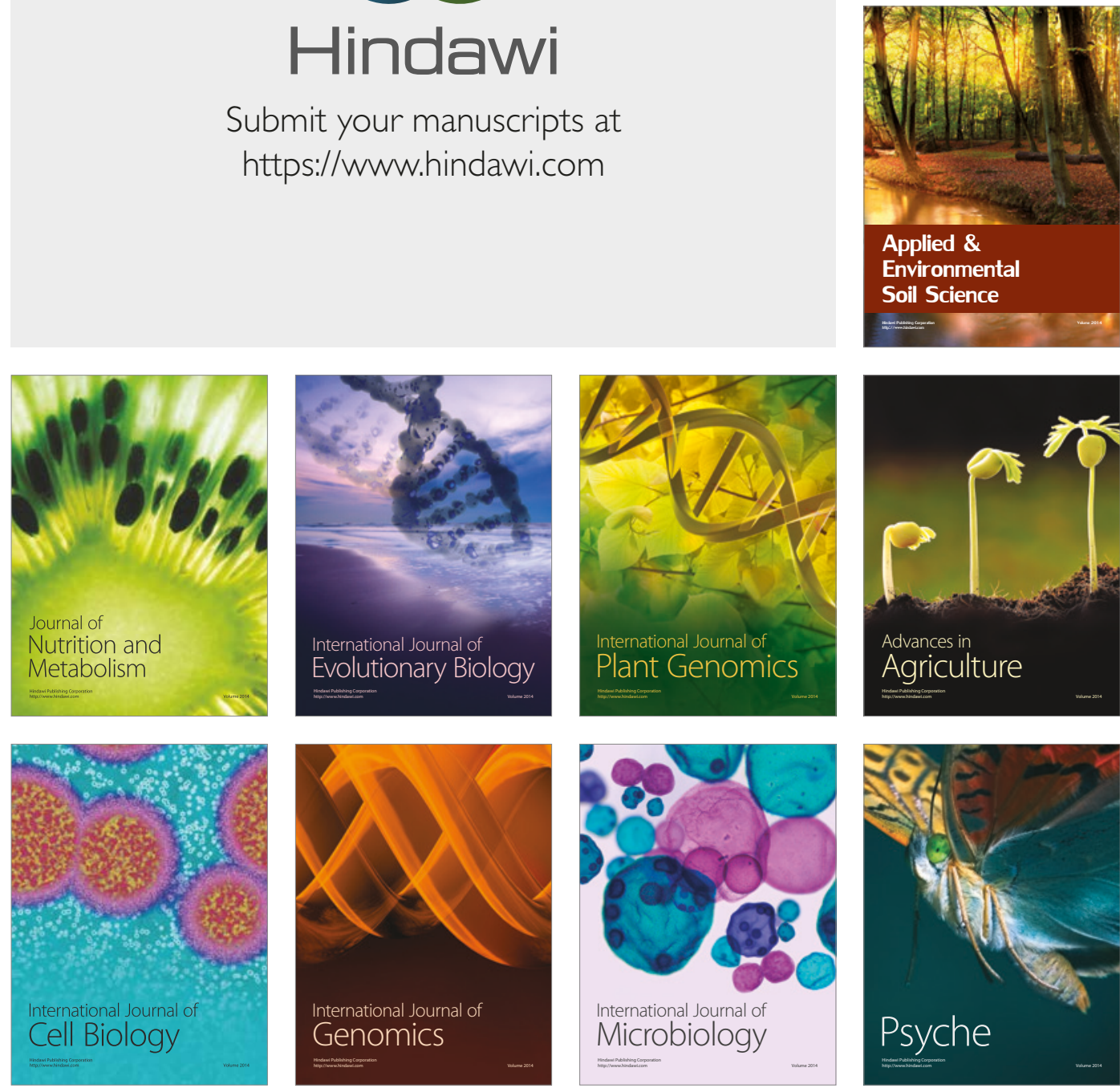

hternational Journal of Microbiology
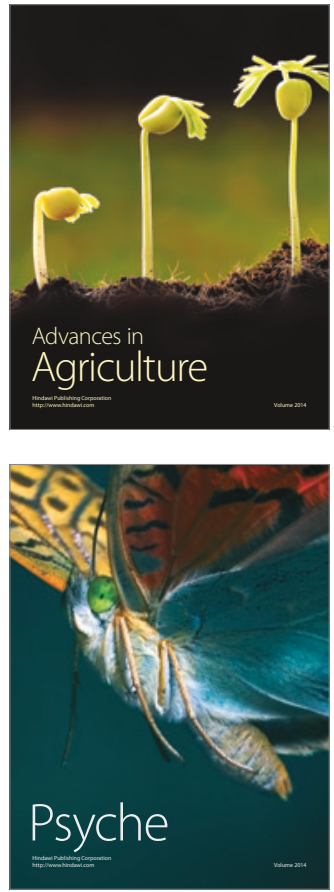